\title{
Constructing Stable and Potentially High-Performance Hybrid Organic-Inorganic Perovskites with "Unstable" Cations
}

\author{
Qing Yang, ${ }^{1}$ Menghao Wu $\mathbb{D}^{1}{ }^{1}$ and Xiao Cheng Zeng ${ }^{2}$ \\ ${ }^{1}$ School of Physics, Huazhong University of Science and Technology, Wuhan, Hubei 430074, China \\ ${ }^{2}$ Department of Chemistry, University of Nebraska, Lincoln, NE 68588, USA \\ Correspondence should be addressed to Menghao Wu; wmh1987@hust.edu.cn and Xiao Cheng Zeng; xzeng1@unl.edu
}

Received 15 March 2020; Accepted 17 May 2020; Published 2 June 2020

Copyright (c) 2020 Qing Yang et al. Exclusive Licensee Science and Technology Review Publishing House. Distributed under a Creative Commons Attribution License (CC BY 4.0).

\begin{abstract}
A new family of functional hybrid organic-inorganic perovskites (HOIPs) is theoretically designed based on the following chemical insights: when a proton is adhered to molecules like water or ethanol, the newly formed larger-sized cations $\left(\right.$ e.g., $\mathrm{H}_{5} \mathrm{O}_{2}{ }^{+}$, $\mathrm{C}_{2} \mathrm{H}_{5} \mathrm{OH}_{2}{ }^{+}$, and $\mathrm{CH}_{3} \mathrm{SH}^{+}$) entail low electron affinities mimicking superalkalis; they are conjugated acids of weak bases that cannot survive in solution, while their chemistry behavior in the HOIP frameworks, however, may be markedly different due to greatly enhanced cohesive energies of the proton, which facilitate the formation of new HOIPs. First-principles computations show that the putative formation reactions for these newly designed HOIPs typically release much more energy compared with the prevailing HOIP $\mathrm{MAPbI}_{3}$, suggesting the likelihood of facile solution-based fabrications, while the suppression of reverse formation suggests that the humidity stability may be markedly enhanced. During their formations, halide acids are unlikely to react with ethanol or methanethiol without the presence of metal halides, a condition further favoring their stability. The proposed structure of $\left(\mathrm{H}_{5} \mathrm{O}_{2}\right) \mathrm{PbI}_{3}$ may also clarify the origin of the long-speculated existence of $\mathrm{HPbI}_{3}$. Importantly, density functional theory computations suggest that many of these HOIPs possess not only direct bandgaps with values within the optimal range for solar light absorbing but also more desirable optical absorption spectra than that of $\mathrm{MAPbI}_{3}$, where their ferroelectric polarizations also benefit photovoltaics. The stability and photovoltaic efficiency may be even further improved for the newly designed two-dimensional (2D) HOIPs and 2D/3D hybrid HOIP structures.
\end{abstract}

\section{Introduction}

Hybrid organic-inorganic perovskites (HOIPs) have attracted intense attention for their high performance in photovoltaics [1-4], achieving a record of power conversion efficiency higher than $25 \%$ within several years $[5,6]$. The general formula of most HOIPs can be written as $\mathrm{ABX}_{3}$, where $\mathrm{A}$ is an organic cation like methylammonium $\mathrm{CH}_{3} \mathrm{NH}_{3}{ }^{+}\left(\mathrm{MA}^{+}\right)$or formamidinium $\left[\mathrm{NH}_{2}\right]_{2} \mathrm{CH}^{+}\left(\mathrm{FA}^{+}\right)$, B is a metal cation like $\mathrm{Pb}^{2+}$ or $\mathrm{Sn}^{2+}$, and $\mathrm{X}$ is a halide anion [1, 7-11]. Historically, HOIP was first fabricated by replacing Cs cations in bulk $\mathrm{CsPbI}_{3}$ with organic groups [12]. Nitrogen-containing organic groups like MA or FA possess low ionization energy (IE), i.e., low electron affinity (EA) of their cations, mimicking superalkalis $[13,14]$. Today, fabrication of HOIPs can be greatly facilitated by mixing the AX and $\mathrm{BX}_{2}$ precursors in solution or in vapor phase, which may be applicable for industry production. For example, $\mathrm{MAPbI}_{3}$ can be synthesized via the reaction $\mathrm{PbI}_{2}+\mathrm{MAI}$ $\longrightarrow \mathrm{MAPbI}_{3}$, forming new $\mathrm{Pb}$-I bonds and bulk perovskite structure. However, the insertion process of MAI species into the $2 \mathrm{D}$ layered $\mathrm{PbI}_{2}$ can be sluggish due to the long diffusion path and strong structure reconstruction, resulting in nonuniform films and incomplete coverage. The synthesis can be further improved by using $\mathrm{HPbI}_{3}$ as a new precursor to replace the lead halide $[15,16]$. The proposed $\mathrm{HPbI}_{3}$ has been a hypothetical structure without any structural or spectroscopic confirmation. Several theoretical studies revealed that $\mathrm{HPbI}_{3}$ is not chemically stable and it readily dissociates into $\mathrm{PbI}_{2}$ and $\mathrm{HI}[17,18]$. It is well known that the IE of the $\mathrm{H}$ atom is $>13 \mathrm{eV}$, a very high value distinctly different from those of alkali metal or MA, whose IE values are $<6 \mathrm{eV}$. Moreover, it is known that stable perovskite structures often satisfy the "tolerance factor," defined as

$$
t=\frac{r_{\mathrm{A}}+r_{\mathrm{X}}}{\sqrt{2}\left(r_{\mathrm{B}}+r_{\mathrm{X}}\right)},
$$




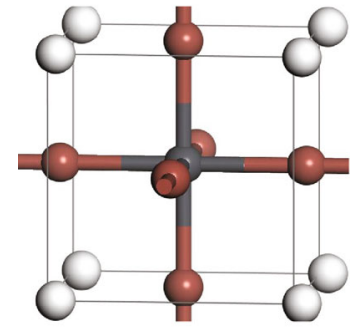

(a)

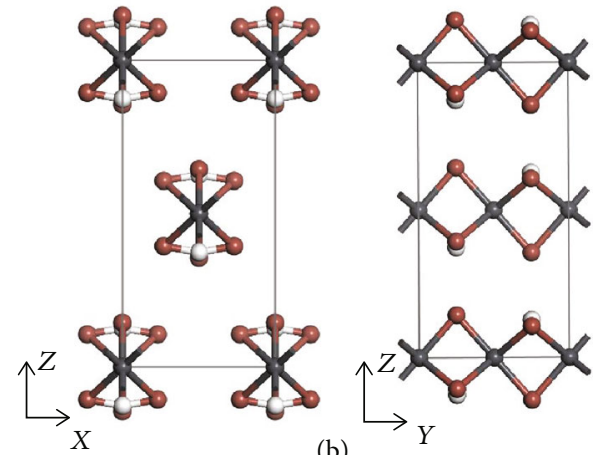

(b)

Figure 1: Geometric structure of the (a) cubic and (b) orthorhombic phases of $\mathrm{HPbI}_{3}$. Grey, brown, and white spheres denote $\mathrm{Pb}$, I, and $\mathrm{H}$ atoms, respectively. Both phases are energetically unfavorable.

where $r_{\mathrm{A}}, r_{\mathrm{B}}$, and $r_{\mathrm{X}}$ represent the effective ionic radii of $\mathrm{A}, \mathrm{B}$, and $\mathrm{X}$ ions, and $t$ should be empirically within the range of $0.76-1.13$. The proton radius is obviously too small and is outside the tolerance factor range for making stable perovskite structures with other ions.

Note that once clustering with water molecules occurs, the proton behaves like alkali cations with much reduced EA and the enlarged ion radius. These value-added features may facilitate the formation of stable perovskite structure. Our ab initio calculations show that $\mathrm{HPbI}_{3}$ is highly unstable while the reaction $\mathrm{PbI}_{2}+\mathrm{HI}+2 \mathrm{H}_{2} \mathrm{O} \longrightarrow\left(\mathrm{H}_{5} \mathrm{O}_{2}\right) \mathrm{PbI}_{3}$ is energetically favorable. This result may clarify the previously speculated existence of $\mathrm{HPbI}_{3}$. The putative formation reaction is akin to the formation of the tin-based compounds like $\left(\mathrm{H}_{5} \mathrm{O}_{2}\right) \mathrm{SnI}_{3}$, which may render fabrication possible by using a mixture of metal dihalides and halide acids as the precursors. Note that this reaction appears to entail much lower formation energy compared with that of the reaction $\mathrm{PbI}_{2}+\mathrm{MAI} \longrightarrow \mathrm{MAPbI}_{3}$. Once bound with some other stable molecules (e.g., $\mathrm{C}_{2} \mathrm{H}_{5} \mathrm{OH}, \mathrm{CH}_{3} \mathrm{SH}$ ), protons may also behave like alkali cations with much reduced EA for making stable perovskites due to the low formation energies. Moreover, we show that several newly predicted HOIPs also possess direct bandgaps in the optimal range of $0.9-1.6 \mathrm{eV}$ as solar absorbers. The ferroelectric polarizations of these newly predicted HOIPs also benefit photovoltaics.

\section{Results}

First, we examined various possible structures of $\mathrm{HPbI}_{3}$. Based on our calculations, the cubic perovskite structure given in the Materials Project database [19] turns out to be highly energetically unfavorable (Figure 1(a)), since a high energy of $3.31 \mathrm{eV} /$ f.u. can be released if decomposed into $\mathrm{PbI}_{2}$ and HI. We construct an orthorhombic phase with the $\mathrm{CmCm}$ symmetry based on face-sharing $\left[\mathrm{PbI}_{6}\right]$ hexagonal stacking structure. This new structure is $2.80 \mathrm{eV} / \mathrm{f}$.u. lower in energy than the cubic structure. As shown in Figure 1(b), the $\mathrm{H}$ atoms are bonded to the surface iodine atoms in the $\left[\mathrm{PbI}_{3}\right]$ chains. Still, such a new structure is still energetically unfavorable since the energy cost $\Delta E$ for the reaction $\mathrm{PbI}_{2}$ $+\mathrm{HI} \longrightarrow \mathrm{HPbI}_{3}$ is $0.51 \mathrm{eV} /$ f.u., which would be endothermic. The unfavorable energetics is due to the small radius of $\mathrm{H}$ and high EA of the proton. However, when the protons are attached to water molecules in solution, larger-sized cations with lower EA would be formed.

Next, we calculate the EA of proton $\mathrm{H}^{+}$binding with 1 and 2 water molecules: $\mathrm{H}_{3} \mathrm{O}^{+}$and $\mathrm{H}_{5} \mathrm{O}_{2}{ }^{+}$, which are, respectively, reduced to 6.4 and $3.1 \mathrm{eV}$, where the latter can be deemed as a superalkali cation. The ground-state geometry of cation $\mathrm{H}_{5} \mathrm{O}_{2}{ }^{+}$is shown in Figure 2(a), where the proton is located at the center of two water molecules. The distances between the central proton and two $\mathrm{O}$ atoms are both $1.21 \AA$, a value between that of the covalent $\mathrm{O}-\mathrm{H}$ bond (usually $1.0 \sim 1.1 \AA$ ) and that of the hydrogen bond (usually 1.4 1.6 ̊). The electron of central $\mathrm{H}$ in $\mathrm{H}_{5} \mathrm{O}_{2}{ }^{+}$is highly delocalized according to the computed electron deformation density. The noncentrosymmetric structure should give rise to a dipole moment. Apart from lower EA, the radius of the cation is also much enlarged, and such larger-sized cations may lead to stable perovskite structures once combined with $\mathrm{PbI}_{2}$. We constructed two perovskite structures by replacing the protons in Figure 1(b) (orthorhombic) and Figure 1(a) (cubic) by $\mathrm{H}_{5} \mathrm{O}_{2}{ }^{+}$, respectively, as shown in Figures 2(b) and 2(c). The computed energy change $\Delta E$ for the formation reaction $\mathrm{PbI}_{2}+\mathrm{HI}+2 \mathrm{H}_{2} \mathrm{O} \longrightarrow\left(\mathrm{H}_{5} \mathrm{O}_{2}\right) \mathrm{PbI}_{3}$ is, respectively, reduced to -0.043 and $0.167 \mathrm{eV} /$ f.u. Here, the lattice parameters $(a=b=8.64 \AA, c=8.13 \AA$ ) for the orthorhombic structure shown in Figure 2(b) appear to be in good agreement with the reported values from fitting the X-ray diffraction pattern [16], and the proposed formation reaction is exothermal, which may account for previously claimed existence of $\mathrm{HPbI}_{3}$.

Note that for the prevailing perovskite $\mathrm{MAPbI}_{3}$, a previous experiment indicates two observed phase transitions, one at $327.4 \mathrm{~K}$ from tetragonal to cubic structure and another at $162.2 \mathrm{~K}$ from orthorhombic to tetragonal structure [20]. Previous DFT calculations $[21,22]$ show that the energy cost for the reaction $\mathrm{PbI}_{2}+\mathrm{MAI} \longrightarrow \mathrm{MAPbI}_{3}$ is, respectively, $0.1 \mathrm{eV} /$ f.u. and $-0.003 \mathrm{eV} / \mathrm{f}$.u. for the formation of the cubic phase and orthorhombic phase. If the cubic structure of $\left(\mathrm{H}_{5} \mathrm{O}_{2}\right) \mathrm{PbI}_{3}$ is replaced by the tetragonal structure in Figure $2(\mathrm{~d})$, which is $0.170 \mathrm{eV} /$ f.u. lower in energy, the reaction would be exothermal with $\Delta E=-0.003 \mathrm{eV} / \mathrm{f}$.u. as well. Meanwhile, thermal stability of the cubic phase of $\left(\mathrm{H}_{5} \mathrm{O}_{2}\right) \mathrm{SnI}_{3}$ at the room temperature can be examined by 


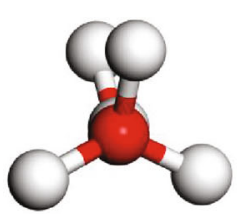

(a)

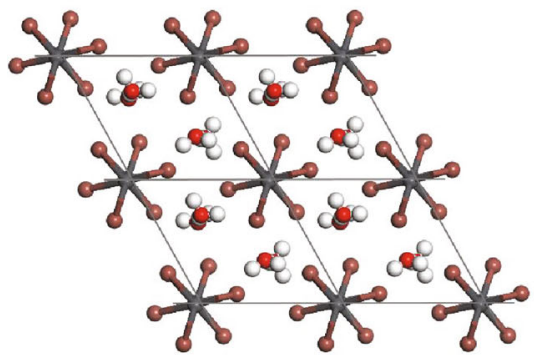

(b)

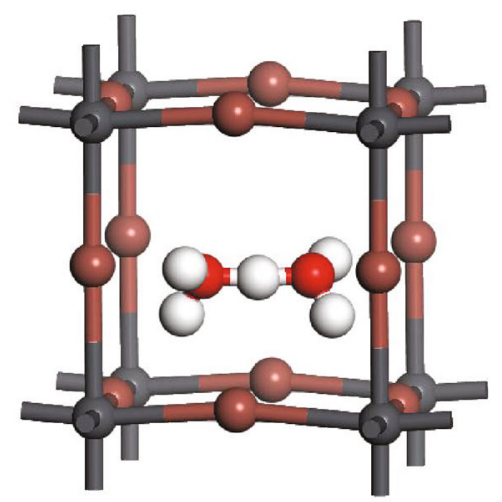

(c)
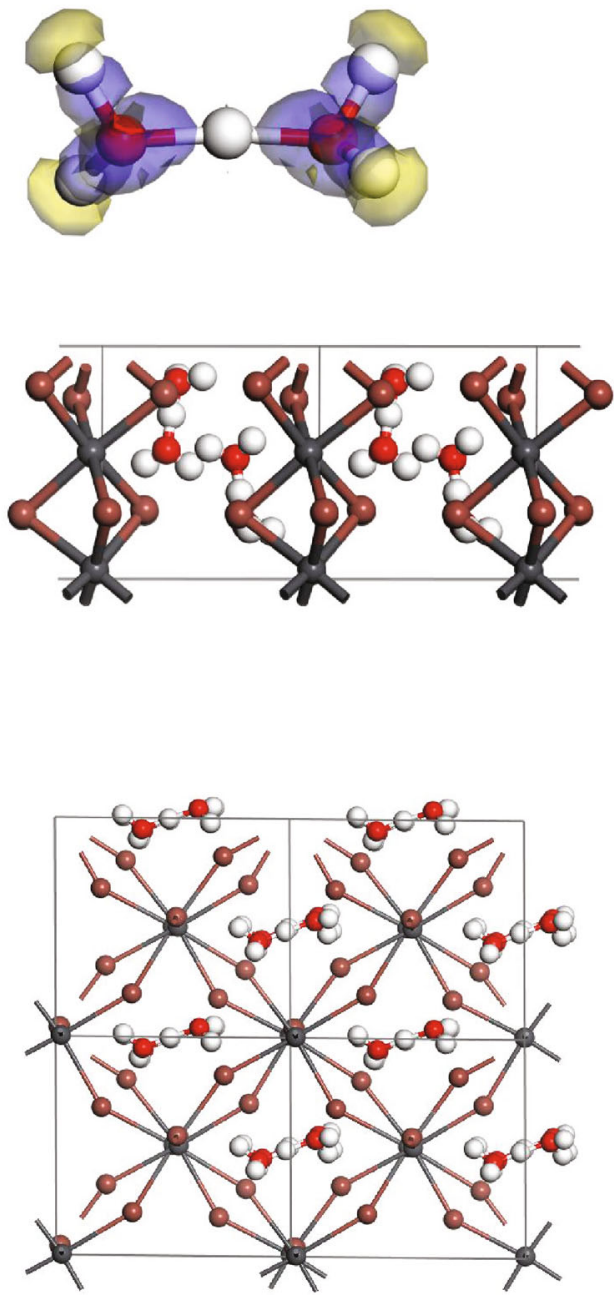

(d)

Figure 2: (a) Structure and computed electron deformation density (side view) of cation $\mathrm{H}_{5} \mathrm{O}_{2}{ }^{+}$. Structure of the (b) orthorhombic, (c) cubic, and (d) tetragonal phases of $\left(\mathrm{H}_{5} \mathrm{O}_{2}\right) \mathrm{PbI}_{3}$.

using ab initio molecular dynamics (AIMD) simulations with the system temperature being controlled at $300 \mathrm{~K}$. The final structure at the end of 5 ps is still intact (see Fig. S1), without showing transformation into the orthorhombic phase. For other alkali atoms, e.g., Li, with much smaller radius compared with $\mathrm{Cs}$, the EA can be reduced from 5.25 to $4.20 \mathrm{eV}$ when attached to a water molecule. As such, the energy cost of the formation of $\mathrm{LiPbI}_{3}$ and $\mathrm{NaPbI}_{3}$ is, respectively, reduced by 1.33 and $0.47 \mathrm{eV} / \mathrm{f}$.u. upon the intercalation of a water molecule attaching to each alkali cation, as shown in Fig. S2.

The formation of the same group of compounds, such as $\left(\mathrm{H}_{5} \mathrm{O}_{2}\right) \mathrm{SnI}_{3}$ and $\left(\mathrm{H}_{5} \mathrm{O}_{2}\right) \mathrm{PbBr}_{3}$, even the cubic phase, can be more energetically favorable:

$$
\begin{gathered}
\mathrm{SnI}_{2}+\mathrm{HI}+2 \mathrm{H}_{2} \mathrm{O} \longrightarrow\left(\mathrm{H}_{5} \mathrm{O}_{2}\right) \mathrm{SnI}_{3}, \Delta E=-0.03 \mathrm{eV} / \mathrm{f} . \mathrm{u} . \\
\mathrm{PbBr}_{2}+\mathrm{HBr}+2 \mathrm{H}_{2} \mathrm{O} \longrightarrow\left(\mathrm{H}_{5} \mathrm{O}_{2}\right) \mathrm{PbBr}_{3}, \Delta E=-0.09 \mathrm{eV} / \mathrm{f} . \mathrm{u} . \\
\mathrm{SnBr}_{2}+\mathrm{HBr}+2 \mathrm{H}_{2} \mathrm{O} \longrightarrow\left(\mathrm{H}_{5} \mathrm{O}_{2}\right) \mathrm{SnBr}_{3}, \Delta E=-0.12 \mathrm{eV} / \mathrm{f} . u
\end{gathered}
$$

So, their solution-based synthesis might be proceeded via deposition of metal dihalide $\mathrm{MX}_{2}$ and halide acid $\mathrm{HX}$ mixture.

We calculate the band structures of the newly predicted stable perovskites by using the HSE+SOC method (see Figure 3(a)). These perovskites all possess direct bandgaps of $0.74,1.43$, and $2.02 \mathrm{eV}$, respectively. $\left(\mathrm{H}_{5} \mathrm{O}_{2}\right) \mathrm{SnI}_{3}$ exhibits perhaps the lowest bandgap among the HOIPs computed using the same approach in the literature. To achieve higher photovoltaic performance (e.g., a Shockley-Queisser efficiency of $\sim 25 \%$ ), direct bandgaps within the optimal range of 0.9-1.6 eV are desired. Here, $\left(\mathrm{H}_{5} \mathrm{O}_{2}\right) \mathrm{PbBr}_{3}$ seems to be an ideal candidate as it possesses a modest bandgap and low $\Delta$ $E$. Note that the photovoltaic performance of most current HOIPs is still poor in the infrared region [26], while the low bandgap HOIPs like $\left(\mathrm{H}_{5} \mathrm{O}_{2}\right) \mathrm{SnI}_{3}$ may fill the gap. The computed optical absorption spectrum (see Figure 3(b)) suggests even stronger absorption compared with $\mathrm{MAPbI}_{3}$ [23], rendering $\left(\mathrm{H}_{5} \mathrm{O}_{2}\right) \mathrm{SnI}_{3}$ a promising candidate as an efficient solar absorber. If the compound of a narrow-bandgap 


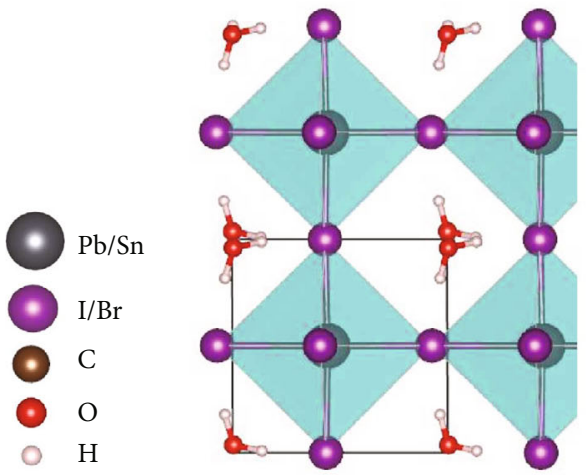

(a)

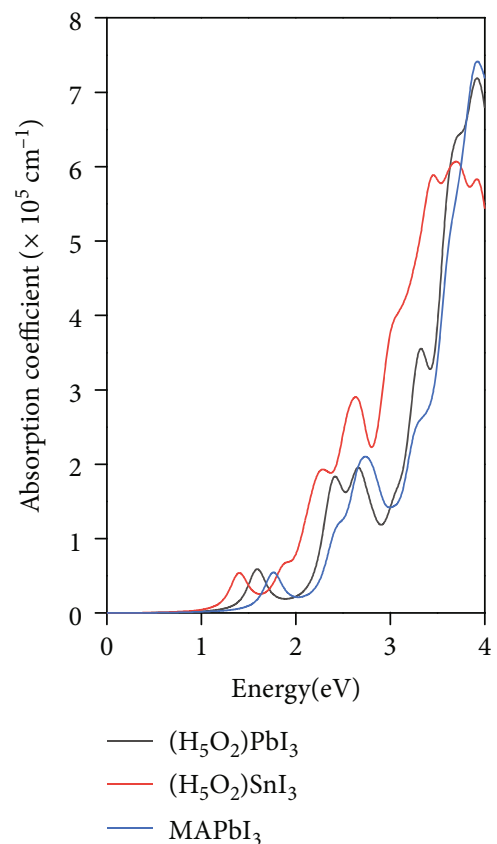

(b)
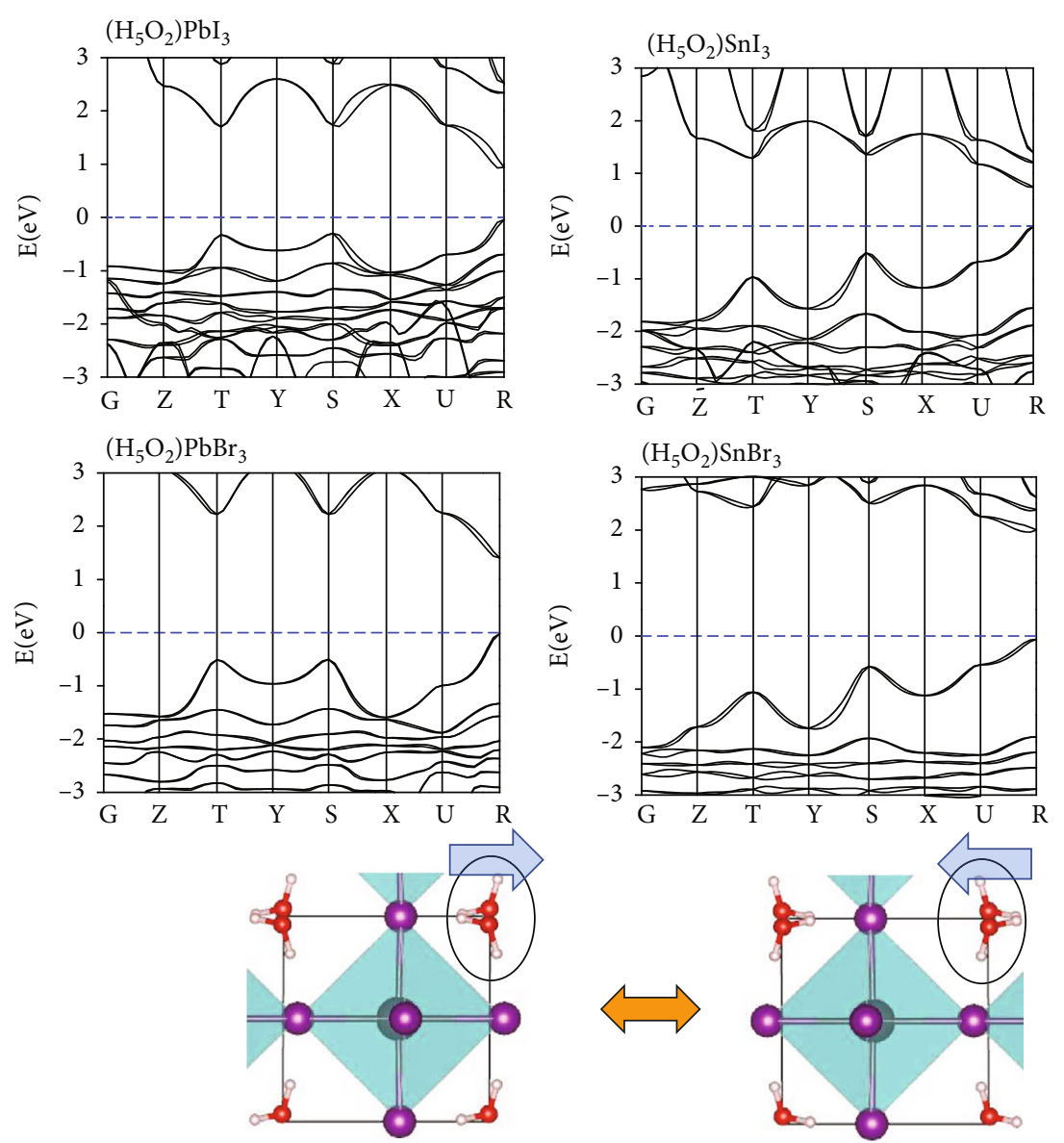

(c)

Figure 3: (a) Computed band structures of the cubic phase $\left(\mathrm{H}_{5} \mathrm{O}_{2}\right) \mathrm{PbI}_{3},\left(\mathrm{H}_{5} \mathrm{O}_{2}\right) \mathrm{SnI}_{3},\left(\mathrm{H}_{5} \mathrm{O}_{2}\right) \mathrm{PbBr}_{3}$, and $\left(\mathrm{H}_{5} \mathrm{O}_{2}\right) \mathrm{SnBr}_{3}$. (b) Computed optical absorption spectra of $\left(\mathrm{H}_{5} \mathrm{O}_{2}\right) \mathrm{PbI}_{3}$ and $\left(\mathrm{H}_{5} \mathrm{O}_{2}\right) \mathrm{SnI}_{3}$. (c) Ferroelectric switching of $\left(\mathrm{H}_{5} \mathrm{O}_{2}\right) \mathrm{SnI}_{3}$. The blue arrows denote the polarization direction of cations and the whole crystal.

$\mathrm{ABX}_{3}$ and a wide-bandgap $\mathrm{A}^{\prime} \mathrm{BX}_{3}$ can be fabricated as $\mathrm{A}_{x} \mathrm{~A}^{\prime}{ }_{1-}$ ${ }_{x} \mathrm{BX}_{3}$, a wider range of bandgaps may be attained via controlling composition $x$, which may be tuned such that the Shockley-Queisser detailed balance limit of photovoltaic conversion efficiency for monobandgap semiconductors could be overpassed. Here, the narrow bandgap of $\left(\mathrm{H}_{5} \mathrm{O}_{2}\right) \mathrm{SnI}_{3}$ and wide bandgap of $\left(\mathrm{H}_{5} \mathrm{O}_{2}\right) \mathrm{SnBr}_{3}$ may be complementary to one another to cover a wider range of spectra. Note also that the absence of centrosymmetry of cation $\mathrm{H}_{5} \mathrm{O}_{2}{ }^{+}$in Figure 2(a) gives rise to polarity. With the reorientations of these polar cations in $\left(\mathrm{H}_{5} \mathrm{O}_{2}\right) \mathrm{SnI}_{3}$ as marked by the circles shown in Figure 3(c), where the blue arrows denote the polarization direction of cations and the whole crystal, a ferroelectric polarization of $22.7 \mu \mathrm{C} / \mathrm{cm}^{2}$ would emerge, much higher than the previously predicted polarization value of $\mathrm{MAPbI}_{3}$ [24]. Theoretically, ferroelectricity may benefit pho- tovoltaics because high photovoltage can be induced by polarization, while photogenerated electrons and holes can be separated by a built-in electric field $[25,26]$. Moreover, combination of a high-mobility narrow-bandgap semiconductor and nonvolatile memory is also desirable [27, 28].

Upon solution mixing of a metal dihalide $\mathrm{MX}_{2}$ and halide acid HX, the halide anions may disassociate from the halide acids and join in the skeleton of the framework, while the protons may be attached to the oxygen atoms of water molecules and form a low-EA cation, mimicking $\mathrm{MA}^{+}$. Aside from water molecules, the proton may also bind with oxygencontaining organic molecules and become cations that may give rise to new and stable HOIPs. Ethanol, for example, can become a cation with $\mathrm{EA}$ of $5.27 \mathrm{eV}$ when binding with a proton at the site of the oxygen atom, as shown in Figure 4(a). As such, energetically favorable perovskite 

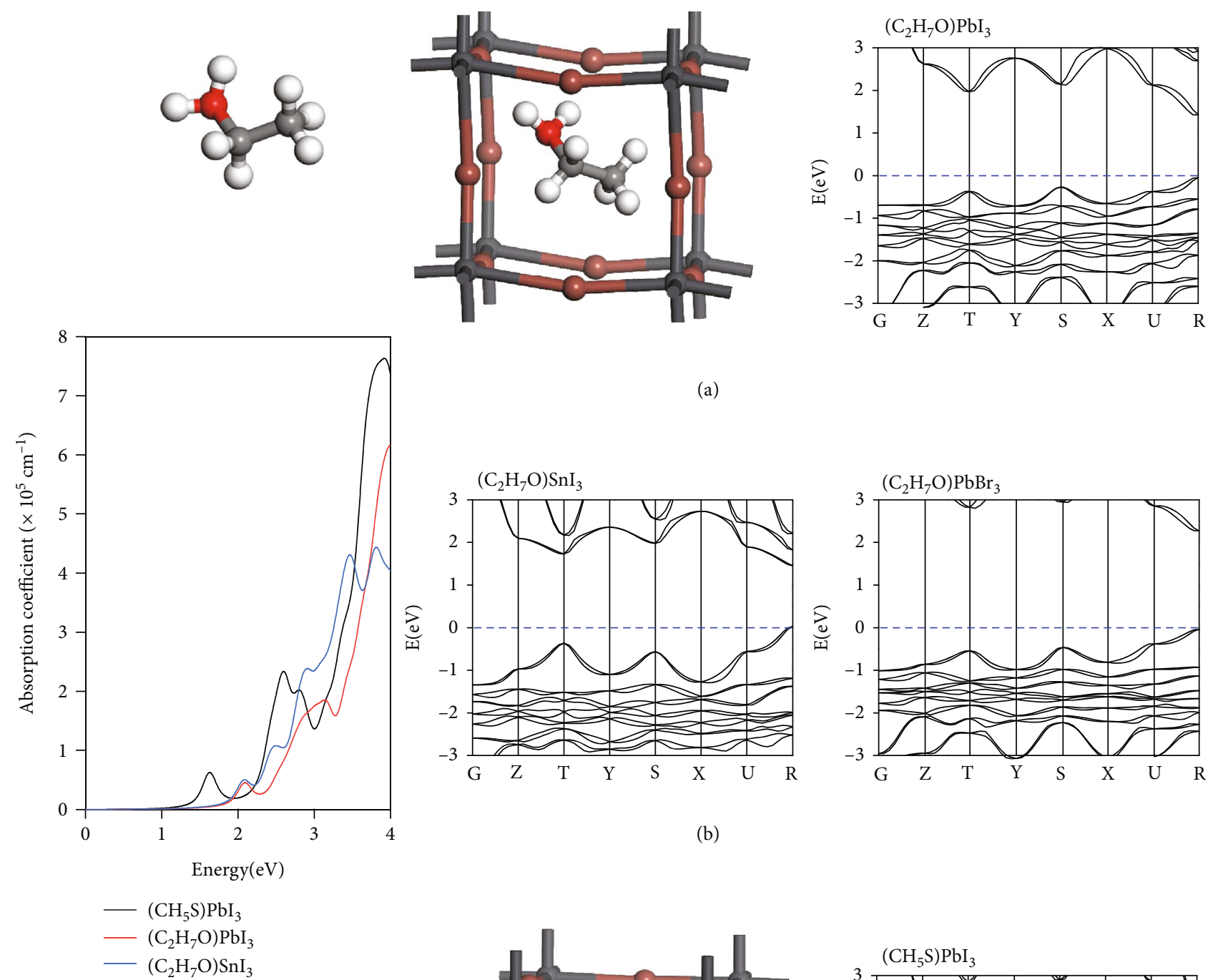

(b)
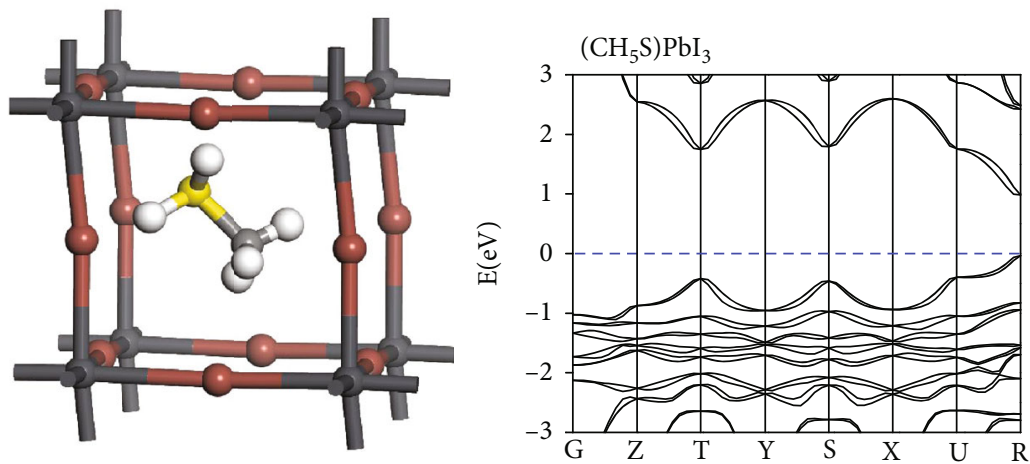

(c)

FIGURE 4: (a) Structure of $\mathrm{C}_{2} \mathrm{H}_{5} \mathrm{OH}_{2}{ }^{+}$cation and related HOIPs and the band structures of HOIPs. (b) Computed optical absorption spectra of $\left(\mathrm{CH}_{5} \mathrm{~S}\right) \mathrm{PbI}_{3},\left(\mathrm{C}_{2} \mathrm{H}_{5} \mathrm{OH}_{2}\right) \mathrm{PbI}_{3}$, and $\left(\mathrm{C}_{2} \mathrm{H}_{5} \mathrm{OH}_{2}\right) \mathrm{SnI}_{3}$. (c) Structures of $\mathrm{CH}_{3} \mathrm{SH}_{2}^{+}$cation and $\left(\mathrm{CH}_{3} \mathrm{SH}_{2}\right) \mathrm{PbI}_{3}$ and the band structures of $\left(\mathrm{CH}_{3} \mathrm{SH}_{2}\right) \mathrm{PbI}_{3}$.

structures can be constructed:

$$
\begin{aligned}
& \mathrm{PbI}_{2}+\mathrm{HI}+\mathrm{C}_{2} \mathrm{H}_{5} \mathrm{OH} \longrightarrow\left(\mathrm{C}_{2} \mathrm{H}_{5} \mathrm{OH}_{2}\right) \mathrm{PbI}_{3}, \Delta E=-0.09 \mathrm{eV} / \text { f.u. } \\
& \mathrm{SnI}_{2}+\mathrm{HI}+\mathrm{C}_{2} \mathrm{H}_{5} \mathrm{OH} \longrightarrow\left(\mathrm{C}_{2} \mathrm{H}_{5} \mathrm{OH}_{2}\right) \mathrm{SnI}_{3}, \Delta E=-0.28 \mathrm{eV} / \text { f.u. }
\end{aligned}
$$

$\mathrm{PbBr}_{2}+\mathrm{HBr}+\mathrm{C}_{2} \mathrm{H}_{5} \mathrm{OH} \longrightarrow\left(\mathrm{C}_{2} \mathrm{H}_{5} \mathrm{OH}_{2}\right) \mathrm{PbBr}_{3}, \Delta E=-0.24$ eV/f.u.

These compounds might be formed in a solution of metal dihalides, halide acids, and ethanol. Here, the halide acids are unlikely to react with ethanol without the presence of metal halides, a condition further favoring the stability of the product HOIPs. In contrast, the high stability of MAI actually disfavors and even lowers the stability of the product $\mathrm{MAPbI}_{3}$, as it only takes $0.003 \mathrm{eV} /$ f.u. for $\mathrm{MAPbI}_{3}$ to decompose into MAI and $\mathrm{PbI}_{2}$ as mentioned above. The thermal stability of $\left(\mathrm{C}_{2} \mathrm{H}_{5} \mathrm{OH}_{2}\right) \mathrm{PbI}_{3}$ is examined via AIMD simulations as shown in Fig. S1. The cubic structure seems be stable at $300 \mathrm{~K}$. Aside 

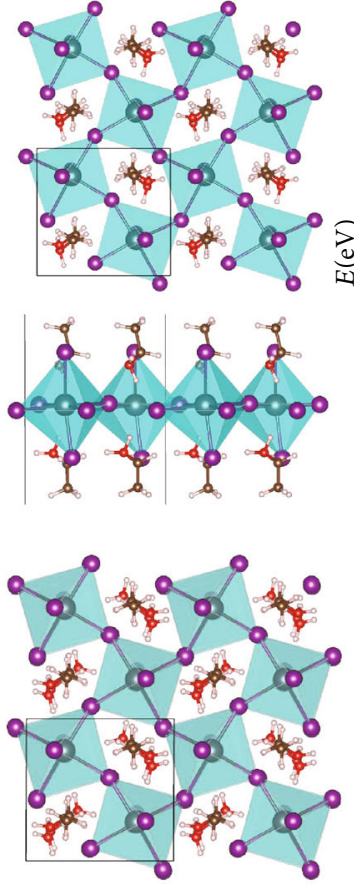

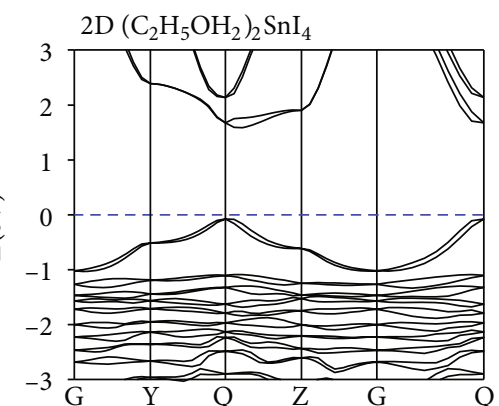

(a)

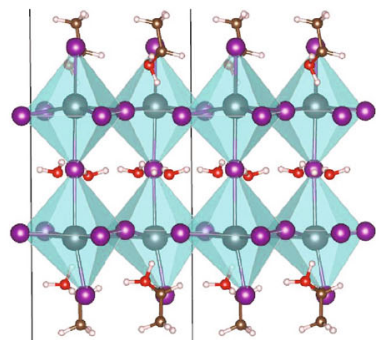

(b)

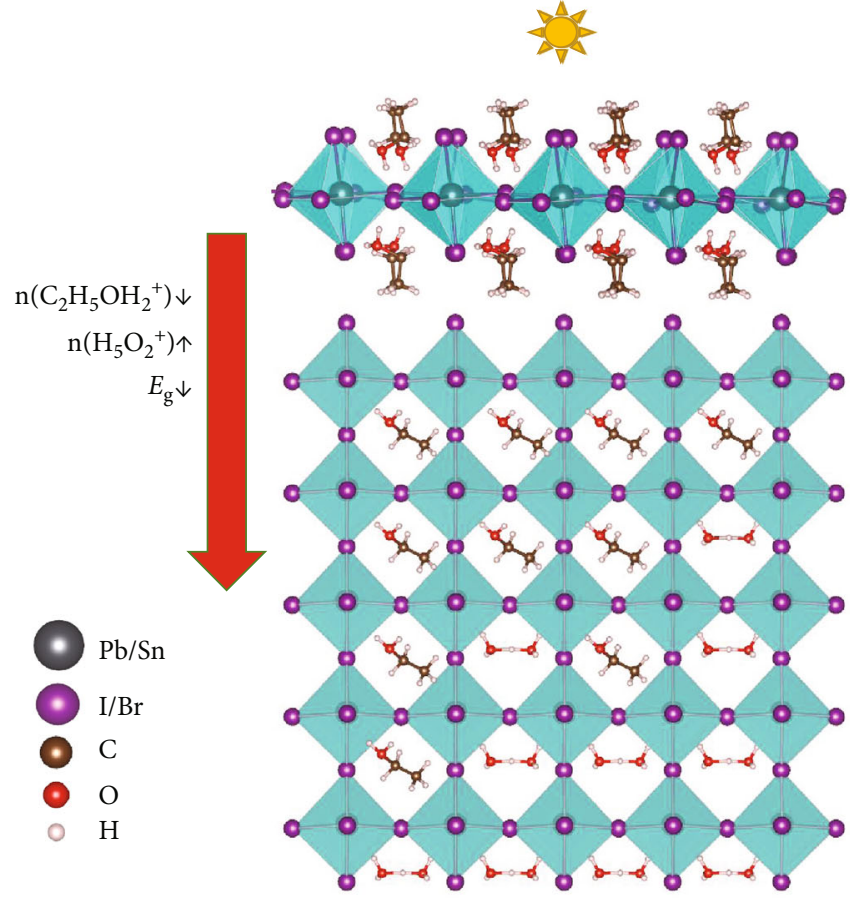

(c)

FIGURE 5: Geometric structure (top and side view) of the $2 \mathrm{D}$ (a) $\left(\mathrm{C}_{2} \mathrm{H}_{5} \mathrm{OH}_{2}\right)_{2} \mathrm{SnI}_{4}$ with its band structure and $(\mathrm{b})\left(\mathrm{H}_{5} \mathrm{O}_{2}\right)\left(\mathrm{C}_{2} \mathrm{H}_{5} \mathrm{OH}_{2}\right){ }_{2} \mathrm{~Pb}_{2} \mathrm{I}_{7}$. (c) A sketch of design by dripping ethanol on the surface of $\left(\mathrm{H}_{5} \mathrm{O}_{2}\right) \mathrm{SnI}_{3}$ to form perovskite (side and top view). The red arrow denotes the dripping direction.

from oxygen, the sulfur atom in a molecule can also be the binding site for the proton. For example, methanethiol can become a cation with EA of $5.33 \mathrm{eV}$ when binding with a proton, as shown in Figure 4(c). The formation reaction for the perovskite with such cations is exothermal: $\mathrm{PbI}_{2}+\mathrm{HI}+\mathrm{CH}_{3}$ $\mathrm{SH} \longrightarrow\left(\mathrm{CH}_{3} \mathrm{SH}_{2}\right) \mathrm{PbI}_{3}, \Delta E=-0.34 \mathrm{eV} / \mathrm{f}$.u. These perovskite structures are energetically much more favorable than $\mathrm{MAPbI}_{3}$, considering their much more energy release upon the formation. Figures 4(a) and 4(c) also display the computed band structures of $\left(\mathrm{C}_{2} \mathrm{H}_{5} \mathrm{OH}_{2}\right) \mathrm{PbI}_{3},\left(\mathrm{C}_{2} \mathrm{H}_{5} \mathrm{OH}_{2}\right) \mathrm{SnI}_{3}$, $\left(\mathrm{C}_{2} \mathrm{H}_{5} \mathrm{OH}_{2}\right) \mathrm{PbBr}_{3}$, and $\left(\mathrm{CH}_{3} \mathrm{SH}_{2}\right) \mathrm{PbI}_{3}$. These perovskites possess direct bandgaps of $1.48,1.47,2.31$, and $1.03 \mathrm{eV}$, respectively, all within the optimal range of $0.9-1.6 \mathrm{eV}$ except $\left(\mathrm{C}_{2} \mathrm{H}_{5} \mathrm{OH}_{2}\right) \mathrm{PbBr}_{3}$. According to the Mulliken charge analysis, the average charges on organic cation, $\mathrm{Pb}$ ion, and I ion are, respectively, $0.65 e, 0.49 e$, and $-0.38 e$ for $\left(\mathrm{C}_{2} \mathrm{H}_{5} \mathrm{OH}_{2}\right) \mathrm{PbI}_{3}$ and $0.62 e, 0.40 e$, and $-0.34 e$ for $\left(\mathrm{CH}_{3} \mathrm{SH}_{2}\right) \mathrm{PbI}_{3}$. It seems that $\left(\mathrm{C}_{2} \mathrm{H}_{5} \mathrm{OH}_{2}\right) \mathrm{PbI}_{3}$ is more ionic, which may explain why it possesses a wider bandgap compared with $\left(\mathrm{CH}_{3} \mathrm{SH}_{2}\right) \mathrm{PbI}_{3}$. It might be the similar case for $\left(\mathrm{C}_{2} \mathrm{H}_{5} \mathrm{OH}_{2}\right) \mathrm{PbBr}_{3}$ with an even wider bandgap as $\mathrm{Br}$ is more electronegative than $\mathrm{I}$. The computed optical absorption spectra are shown in Figure 4(b), exhibiting even stronger absorption compared with that of $\mathrm{MAPbI}_{3}$. The major factor that causes the difference in the optical absorption might be attributed to different bandgaps, as shown by the redshift of the spectrum for $\left(\mathrm{CH}_{3} \mathrm{SH}_{2}\right) \mathrm{PbI}_{3}$ due to its smaller bandgap compared with other HOIPs. Similarly, the absence of centrosymmetry of cations (as shown in Figures 4(a) and 4(c)) would also give rise to polarity. With the reorientations of these polar cations as marked by the cir- cles shown in Fig. S3(c), where the blue arrows denote the polarization direction of cations and the whole crystal, considerable polarizations would emerge for both $\left(\mathrm{C}_{2} \mathrm{H}_{5} \mathrm{OH}_{2}\right) \mathrm{PbI}_{3}$ and $\left(\mathrm{CH}_{4} \mathrm{SH}\right) \mathrm{PbI}_{3}$. Distinct from $\left(\mathrm{H}_{5} \mathrm{O}_{2}\right) \mathrm{SnI}_{3}$, here, their polarizations possess projection along both the $-x$ and $-y$ axes in Fig. S3. The computed $P_{x}$ and $P_{y}$ are, respectively, 11.08 and $10.98 \mu \mathrm{C} / \mathrm{cm}^{2}$ for $\left(\mathrm{C}_{2} \mathrm{H}_{5} \mathrm{OH}_{2}\right) \mathrm{PbI}_{3}$ and 7.65 and $1.68 \mu \mathrm{C} / \mathrm{cm}^{2}$ for $\left(\mathrm{CH}_{4} \mathrm{SH}\right) \mathrm{PbI}_{3}$.

Depending on the radius of the cations, the $1 \mathrm{D}, 2 \mathrm{D}$, or $3 \mathrm{D}$ perovskite frameworks may be formed: the $3 \mathrm{D}$ frameworks tend to form with smaller cations like MA, while larger cations such as $\mathrm{Ph}\left(\mathrm{CH}_{2}\right) 2 \mathrm{NH}_{3}$ (PEA) [29, 30] tend to form lowdimensional structures. We note that the cation $\left(\mathrm{C}_{2} \mathrm{H}_{5} \mathrm{OH}_{2}\right)^{+}$ is already larger than $\mathrm{MA}^{+}$. A $2 \mathrm{D}$ structure of $\left(\mathrm{C}_{2} \mathrm{H}_{5} \mathrm{OH}_{2}\right)_{2} \mathrm{SnI}_{4}$ is constructed in Figure 5(a), a typical Ruddlesden-Popper perovskite structure consisting a layer of corner-sharing [SnI 6 octahedral interleaved with $\left(\mathrm{C}_{2} \mathrm{H}_{5} \mathrm{OH}_{2}\right)^{+}$cations on both surfaces. The following formation reactions of the same group of compounds are all exothermic:

$\mathrm{PbI}_{2}+2 \mathrm{HI}+2 \mathrm{C}_{2} \mathrm{H}_{5} \mathrm{OH} \longrightarrow\left(\mathrm{C}_{2} \mathrm{H}_{5} \mathrm{OH}_{2}\right)_{2} \mathrm{PbI}_{4}, \Delta E=-0.57 \mathrm{eV} / \mathrm{f} . \mathrm{u}$.

$\mathrm{SnI}_{2}+2 \mathrm{HI}+2 \mathrm{C}_{2} \mathrm{H}_{5} \mathrm{OH} \longrightarrow\left(\mathrm{C}_{2} \mathrm{H}_{5} \mathrm{OH}_{2}\right)_{2} \mathrm{SnI}_{4}, \Delta E=-0.65 \mathrm{eV} /$ f.u.

$\mathrm{PbI}_{2}+2 \mathrm{HBr}+2 \mathrm{C}_{2} \mathrm{H}_{5} \mathrm{OH} \longrightarrow\left(\mathrm{C}_{2} \mathrm{H}_{5} \mathrm{OH}_{2}\right)_{2} \mathrm{PbBr}_{4}, \Delta E=-0.70 \mathrm{eV} /$ f.u.

Here, the energy release per each organic cation is even higher compared to the formation of the corresponding $3 \mathrm{D}$ structures in Figure 4(a); thereby, the low-dimensional 
structures are more likely to be formed. The thermal stability of $\left(\mathrm{C}_{2} \mathrm{H}_{5} \mathrm{OH}_{2}\right)_{2} \mathrm{PbI}_{4}$ is examined via AIMD simulations (Fig. S1); and the $2 \mathrm{D}$ structure can be stable at $350 \mathrm{~K}$. Previous studies of the 2D Ruddlesden-Popper perovskite usually show higher stability but an undesirable wide bandgap $(\sim 3 \mathrm{eV})$ compared with the $3 \mathrm{D}$ perovskites. Notably, the bandgap of the $2 \mathrm{D}$
$\left(\mathrm{C}_{2} \mathrm{H}_{5} \mathrm{OH}_{2}\right)_{2} \mathrm{SnI}_{4}$ is $\sim 1.7 \mathrm{eV}$ (Figure 5(a)), which is in the desirable range. If water is also involved in the precursors, the smaller cations $\mathrm{H}_{5} \mathrm{O}_{2}{ }^{+}$may be intercalated in the central layer of the 2D Ruddlesden-Popper perovskite structure, as shown in Figure 5(b):

$$
\begin{gathered}
2 \mathrm{PbI}_{2}+3 \mathrm{HI}+2 \mathrm{H}_{2} \mathrm{O}+2 \mathrm{C}_{2} \mathrm{H}_{5} \mathrm{OH} \longrightarrow\left(\mathrm{H}_{5} \mathrm{O}_{2}\right)\left(\mathrm{C}_{2} \mathrm{H}_{5} \mathrm{OH}_{2}\right)_{2} \mathrm{~Pb}_{2} \mathrm{I}_{7}, \Delta E=-0.46 \mathrm{eV} / \mathrm{f} . u . \\
2 \mathrm{SnI}_{2}+3 \mathrm{HI}+2 \mathrm{H}_{2} \mathrm{O}+2 \mathrm{C}_{2} \mathrm{H}_{5} \mathrm{OH} \longrightarrow\left(\mathrm{H}_{5} \mathrm{O}_{2}\right)\left(\mathrm{C}_{2} \mathrm{H}_{5} \mathrm{OH}_{2}\right)_{2} \mathrm{Sn}_{2} \mathrm{I}_{7}, \Delta E=-0.77 \mathrm{eV} / \mathrm{f} . u . \\
2 \mathrm{PbBr}_{2}+3 \mathrm{HBr}+2 \mathrm{H}_{2} \mathrm{O}+2 \mathrm{C}_{2} \mathrm{H}_{5} \mathrm{OH} \longrightarrow\left(\mathrm{H}_{5} \mathrm{O}_{2}\right)\left(\mathrm{C}_{2} \mathrm{H}_{5} \mathrm{OH}_{2}\right)_{2} \mathrm{~Pb}_{2} \mathrm{Br}_{7}, \Delta E=-0.77 \mathrm{eV} / \mathrm{f} . u
\end{gathered}
$$

Finally, we present a structure design, akin to a chemical multijunction, for achieving spatially varying bandgaps over a wide range, which may potentially surpass the ShockleyQueisser detailed balance limit of photovoltaic conversion efficiency for monobandgap semiconductors. Figure 5(c) illustrates a schematic plot of dripping ethanol on the surface of $\left(\mathrm{H}_{5} \mathrm{O}_{2}\right) \mathrm{SnI}_{3}$. With the permeation of ethanol, a density gradient of cations can be formed. The formation energy of $\left(\mathrm{C}_{2} \mathrm{H}_{5} \mathrm{OH}_{2}\right) \mathrm{SnI}_{3}$ is lower than $\left(\mathrm{H}_{5} \mathrm{O}_{2}\right) \mathrm{SnI}_{3}$, so $\mathrm{H}_{5} \mathrm{O}_{2}{ }^{+}$can be substituted. Since the following reactions are mentioned above,

$$
\begin{gathered}
\mathrm{SnI}_{2}+\mathrm{HI}+2 \mathrm{H}_{2} \mathrm{O} \longrightarrow\left(\mathrm{H}_{5} \mathrm{O}_{2}\right) \mathrm{SnI}_{3}, \Delta E=-0.03 \mathrm{eV} / \text { f.u. } \\
\mathrm{SnI}_{2}+\mathrm{HI}+\mathrm{C}_{2} \mathrm{H}_{5} \mathrm{OH} \longrightarrow\left(\mathrm{C}_{2} \mathrm{H}_{5} \mathrm{OH}_{2}\right) \mathrm{SnI}_{3}, \Delta E=-0.28 \mathrm{eV} / \text { f.u. }
\end{gathered}
$$

the reaction below can be inferred:

$\left(\mathrm{H}_{5} \mathrm{O}_{2}\right) \mathrm{SnI}_{3}+\mathrm{C}_{2} \mathrm{H}_{5} \mathrm{OH} \longrightarrow\left(\mathrm{C}_{2} \mathrm{H}_{5} \mathrm{OH}_{2}\right) \mathrm{SnI}_{3}+2 \mathrm{H}_{2} \mathrm{O}, \Delta E=-0.25 \mathrm{eV} / \mathrm{f} . \mathrm{u}$.

The computed bandgap decreases from $1.47 \mathrm{eV}$ of $\left(\mathrm{C}_{2} \mathrm{H}_{5} \mathrm{OH}_{2}\right) \mathrm{SnI}_{3}$ at the surface to $0.73 \mathrm{eV}$ of $\left(\mathrm{H}_{5} \mathrm{O}_{2}\right) \mathrm{SnI}_{3}$ inside the structure due to the decreasing density as $\mathrm{C}_{2} \mathrm{H}_{5} \mathrm{OH}_{2}{ }^{+}$substitutes $\mathrm{H}_{5} \mathrm{O}_{2}{ }^{+}$during the permeation of ethanol. On the surface, with the highest density of ethanol, the $2 \mathrm{D}$ structure of $\left(\mathrm{C}_{2} \mathrm{H}_{5} \mathrm{OH}_{2}\right)_{2} \mathrm{SnI}_{4}$ may be formed if the $\mathrm{HI}$ solution is dripped in the final step.

Likewise, since the following reaction is mentioned above,

$\mathrm{SnI}_{2}+2 \mathrm{HI}+2 \mathrm{C}_{2} \mathrm{H}_{5} \mathrm{OH} \longrightarrow\left(\mathrm{C}_{2} \mathrm{H}_{5} \mathrm{OH}_{2}\right)_{2} \mathrm{SnI}_{4}, \Delta E=-0.65 \mathrm{eV} / \mathrm{f}$.u.

the reactions below can be inferred:

$$
\begin{gathered}
\left(\mathrm{H}_{5} \mathrm{O}_{2}\right) \mathrm{SnI}_{3}+\mathrm{HI}+2 \mathrm{C}_{2} \mathrm{H}_{5} \mathrm{OH} \longrightarrow\left(\mathrm{C}_{2} \mathrm{H}_{5} \mathrm{OH}_{2}\right)_{2} \mathrm{SnI}_{4}+2 \mathrm{H}_{2} \mathrm{O}, \Delta E=-0.62 \mathrm{eV} / \mathrm{f} . \mathrm{u} . \\
\left(\mathrm{C}_{2} \mathrm{H}_{5} \mathrm{OH}_{2}\right) \mathrm{SnI}_{3}+\mathrm{HI}+\mathrm{C}_{2} \mathrm{H}_{5} \mathrm{OH} \longrightarrow\left(\mathrm{C}_{2} \mathrm{H}_{5} \mathrm{OH}_{2}\right)_{2} \mathrm{SnI}_{4}, \Delta E=-0.37 \mathrm{eV} / \mathrm{f} . \mathrm{u} .
\end{gathered}
$$

Such a 2D layer covered by hydrophobic ligands and with a higher bandgap of $1.7 \mathrm{eV}$ may be utilized as a cover layer to protect the perovskite structure, while enhancing the light absorption in the ultraviolet region. Meanwhile, the switchable polar ligands also give rise to an in-plane $2 \mathrm{D}$ ferroelectricity of $1.2 \times 10^{-10} \mathrm{C} / \mathrm{m}$, which can facilitate the separation of electrons and holes. Such a structure design may render high photovoltaic efficiency due to the desirable spatially varying bandgaps, ranging from 0.7 to $1.7 \mathrm{eV}$.

\section{Discussions}

It is known that the structure instability of $\mathrm{MAPbI}_{3}$ stems in part from the tendency of reversing the formation reaction. As mentioned above, for $\mathrm{PbI}_{2}+\mathrm{MAI} \longrightarrow \mathrm{MAPbI}_{3}, \Delta E=-3$ $\mathrm{meV} / \mathrm{f}$.u., so the energy cost of reverse reaction is only $3 \mathrm{meV} / \mathrm{f}$.u. However, for the abovementioned formation reactions such as $\mathrm{SnI}_{2}+\mathrm{HI}+\mathrm{C}_{2} \mathrm{H}_{5} \mathrm{OH} \longrightarrow\left(\mathrm{C}_{2} \mathrm{H}_{5} \mathrm{OH}_{2}\right) \mathrm{SnI}_{3}$ , $\Delta E=-0.28 \mathrm{eV} /$ f.u.; $\mathrm{PbI}_{2}+\mathrm{HI}+\mathrm{CH}_{3} \mathrm{SH} \longrightarrow\left(\mathrm{CH}_{3} \mathrm{SH}_{2}\right) \mathrm{Pb}$ 
$\mathrm{I}_{3}, \quad \Delta E=-0.34 \mathrm{eV} /$ f.u.; and $\mathrm{SnI}_{2}+2 \mathrm{HI}+2 \mathrm{C}_{2} \mathrm{H}_{5} \mathrm{OH} \longrightarrow$ $\left(\mathrm{C}_{2} \mathrm{H}_{5} \mathrm{OH}_{2}\right)_{2} \mathrm{SnI}_{4}, \Delta E=-0.65 \mathrm{eV} / \mathrm{f}$.u., the corresponding reverse reactions become very unlikely due to the high energy cost. Their structural stability might be partially attributed their moderate tolerance factors $t$, which are calculated by using equation (1) and listed in Table S1. For stable structures, $t$ should be empirically within the range of 0.76 1.13. It turns out that the $t$ factors for all the structures with cations $\mathrm{H}_{5} \mathrm{O}_{2}^{+}, \mathrm{C}_{2} \mathrm{H}_{5} \mathrm{OH}_{2}^{+}$, or $\mathrm{CH}_{3} \mathrm{SH}^{+}$as listed in Table $\mathrm{S} 1$ are within this range. The thermal stabilities of the three compounds are also examined (see Fig. S1).

The chemical stability of the newly designed perovskites may be unexpected, as the cations considered in this study are conjugated acids of very weak bases $\left(\mathrm{H}_{5} \mathrm{O}_{2}{ }^{+}, \mathrm{pKa}=-\right.$ 1.74; $\mathrm{C}_{2} \mathrm{H}_{5} \mathrm{OH}_{2}{ }^{+}, \mathrm{pKa}=-2.4$; and $\left.\mathrm{CH}_{3} \mathrm{SH}_{2}^{+}, \mathrm{pKa}=-5.4\right)$ in the Brønsted-Lowry acid-base theory. Our calculations show that the binding energy for a proton attaching to a $\mathrm{C}_{2} \mathrm{H}_{5} \mathrm{OH}$ or $\mathrm{CH}_{3} \mathrm{SH}$ molecule is 0.41 or $0.85 \mathrm{eV}$ lower compared to that of $\mathrm{H}_{3} \mathrm{O}^{+}$(binding a proton to a water molecule). As such, $\left(\mathrm{C}_{2} \mathrm{H}_{5} \mathrm{OH}_{2}\right)^{+}$and $\left(\mathrm{CH}_{3} \mathrm{SH}_{2}\right)^{+}$are less likely to form in solution as the protons tend to bind with water molecules. However, the adsorption of the proton would be enhanced in the solid HOIP frameworks. For example, the energy cost for a water molecule to take away a proton from the $2 \mathrm{D}$ $\left(\mathrm{C}_{2} \mathrm{H}_{5} \mathrm{OH}_{2}\right)_{2} \mathrm{PbI}_{4}$ would amount to $2.3 \mathrm{eV}$. It has been suggested in previous studies $[31,32]$ that the poor humidity stability of $\mathrm{MAPbI}_{3}$ can be attributed to the trapped charges:

$$
\begin{gathered}
\mathrm{I}^{-}+\mathrm{H}_{2} \mathrm{O} \longrightarrow \mathrm{HI}+\mathrm{OH}^{-} \\
\mathrm{OH}^{-}+\mathrm{H}_{2} \mathrm{O} \longrightarrow \mathrm{H}_{2} \mathrm{O}+\mathrm{OH}^{-} \\
\mathrm{CH}_{3} \mathrm{NH}_{3}{ }^{+}+\mathrm{OH}^{-} \longrightarrow \mathrm{CH}_{3} \mathrm{NH}_{2}+\mathrm{H}_{2} \mathrm{O}
\end{gathered}
$$

By similar simulation with a trapped charge, however, the energy cost for a hydroxyl ion to take away a proton from $\left(\mathrm{H}_{5} \mathrm{O}_{2}\right) \mathrm{PbI}_{3}$ and $\left(\mathrm{CH}_{3} \mathrm{SH}_{2}\right) \mathrm{PbI}_{3}$ would be, respectively, 1.94 and $1.80 \mathrm{eV}$, indicating potentially high humidity stability. Since there are other possible mechanisms of decomposition, we cannot guarantee that the newly designed systems can survive in the high humidity. However, it is highly likely that their humidity stability is markedly enhanced compared with the benchmark perovskite $\mathrm{MAPbI}_{3}$.

\section{Conclusions}

In conclusion, we have shown a series of superalkali cations with a relatively large radius and much reduced electron affinity (e.g., $\mathrm{H}_{5} \mathrm{O}_{2}^{+}, \mathrm{C}_{2} \mathrm{H}_{5} \mathrm{OH}_{2}^{+}$, and $\mathrm{CH}_{3} \mathrm{SH}_{2}^{+}$) through adding protons to prevailing molecules like water or ethanol, which notably enrich the number of cation candidates for perovskite synthesis. Even though these cations are less stable in solution due to their chemical nature of conjugated acids of weak bases, they become much more stable within the perovskite frameworks due to their high binding energies with the proton. As a result, they could potentially form new and stable hybrid perovskites like $\left(\mathrm{H}_{5} \mathrm{O}_{2}\right) \mathrm{SnI}_{3}$, $\left(\mathrm{C}_{2} \mathrm{H}_{5} \mathrm{OH}_{2}\right) \mathrm{SnI}_{3}$, and $\left(\mathrm{CH}_{3} \mathrm{SH}_{2}\right) \mathrm{PbI}_{3}$. For these compounds, the formation reactions are predicted to be exothermic with much more energy release compared with the prevailing
$\mathrm{MAPbI}_{3}$, which may enable facile solution-processed fabrication, and the reverse reactions will be suppressed due to the high energy costs. Many of these newly predicted perovskites possess not only direct bandgaps within the optimal range for solar absorbing but also more desired optical absorption spectra compared with that of $\mathrm{MAPbI}_{3}$. Lastly, the $2 \mathrm{D}$ and 2D/3D hybrid perovskite structures are also predicted to be energetically highly favorable due to their high formation energies. If confirmed in the laboratory, special perovskite designs with novel spatially varying bandgaps over a wide energy range may be achieved to offer high photovoltaic efficiency.

\section{Computational Methods}

Our density functional theory (DFT) calculations are performed using the Vienna $\mathrm{Ab}$ initio Simulation Package (VASP 5.3.4) code $[33,34]$. The electron-ion interaction is described by the projector augmented wave (PAW) method [35], and the generalized gradient approximation (GGA) in the Perdew-Burke-Ernzerhof (PBE) form is applied [36]. The plane wave cutoff energy for a wave function is set to $500 \mathrm{eV}$. The $9 \times 9 \times 9$ Monkhorst-Pack $k$-point mesh is employed for sampling the Brillouin zone [37]. The lattice parameters and atomic positions are fully relaxed until the energy difference is less than $10^{-6} \mathrm{eV}$ and the force on each atom is smaller than $0.01 \mathrm{eV} / \AA$. Since the conventional GGA functional like PBE tends to underestimate the bandgaps, the Heyd-Scuseria-Ernzerhof (HSE06) hybrid functional is also used to compute the electronic structures and optical properties [38] while taking into account the spinorbit coupling (SOC) effect. As for the $2 \mathrm{D}$ structure, a vacuum region of $15 \AA$ is added to the vertical direction to neglect the interaction between the neighboring layers. According to previous reports $[39,40]$, the accuracy of DFT computations can be enhanced by using dispersion correction when calculating dispersion effects in perovskites and related compounds. We have examined our results by using the D2 functional of Grimme [41] to take the van der Waals interaction into account. Taking the formation reaction $\mathrm{Pb}$ $\mathrm{I}_{2}+\mathrm{HI}+2 \mathrm{H}_{2} \mathrm{O} \longrightarrow\left(\mathrm{H}_{5} \mathrm{O}_{2}\right) \mathrm{PbI}_{3}$ as a paradigmatic case, $\Delta E$ computed by using $\mathrm{PBE}+\mathrm{D} 2$ is $0.187 \mathrm{eV} / \mathrm{f}$.u., slightly higher than $0.167 \mathrm{eV} / \mathrm{f}$.u. based on the PBE functional.

The Berry phase method is employed to evaluate crystalline polarization [42]. For optical properties, we first compute the frequency-dependent complex dielectric function and then the absorption coefficient based on the equation:

$$
\alpha(\bar{\omega})=\frac{\sqrt{2} e}{\hbar c}\left[\left(\varepsilon_{1}{ }^{2}+\varepsilon_{2}{ }^{2}\right)^{1 / 2}-\varepsilon_{1}{ }^{2}\right]^{1 / 2},
$$

where $\varepsilon_{1}$ and $\varepsilon_{2}$ are the real and imaginary parts of the dielectric function, respectively. The formation energy associated with the reaction $\mathrm{A}+\mathrm{B}+\mathrm{C} \longrightarrow \mathrm{D}$ is computed based on the formula, $\Delta E=E(\mathrm{D})-E(\mathrm{~A})-E(\mathrm{~B})-E(\mathrm{C})$, where each term is the energy of the corresponding crystal structure. The ab initio molecular dynamics (AIMD) simulations are also performed using the VASP code, where the canonical 
ensemble, the algorithm of Nosè, and a time step of $1 \mathrm{fs}$ are adopted.

\section{Conflicts of Interest}

The authors declare that there is no conflict of interest regarding the publication of this article.

\section{Acknowledgments}

MHW is supported by the National Natural Science Foundation of China (No. 21573084). We thank Dr. Minggang Ju, Dr. Jun Dai, and Dr. Yuanyuan Zhou for helpful discussions.

\section{Supplementary Materials}

Figure S1: snapshots of $\left(\mathrm{H}_{5} \mathrm{O}_{2}\right) \mathrm{PbI}_{3}$ and $\left(\mathrm{C}_{2} \mathrm{H}_{5} \mathrm{OH}_{2}\right) \mathrm{PbI}_{3}$ at $300 \mathrm{~K}$ and $\left(\mathrm{C}_{2} \mathrm{H}_{5} \mathrm{OH}_{2}\right)_{2} \mathrm{PbI}_{4}$ at $350 \mathrm{~K}$, taken from ab initio molecular dynamics simulations at the end of $5 \mathrm{ps}$. Figure S2: geometric structure of $\mathrm{Na}\left(\mathrm{H}_{2} \mathrm{O}\right) \mathrm{PbI}_{3}$. Table S1: tolerance factors of various cubic HOIPs. Figure S3: ferroelectric switching of (a) $\left(\mathrm{C}_{2} \mathrm{H}_{5} \mathrm{OH}_{2}\right) \mathrm{PbI}_{3}$ and (b) $\left(\mathrm{CH}_{4} \mathrm{SH}\right) \mathrm{PbI} 3$. The blue arrows denote the polarization directions. (Supplementary Materials)

\section{References}

[1] A. Kojima, K. Teshima, Y. Shirai, and T. Miyasaka, "Organometal halide perovskites as visible-light sensitizers for photovoltaic cells," Journal of the American Chemical Society, vol. 131, no. 17, pp. 6050-6051, 2009.

[2] L. Etgar, P. Gao, Z. Xue et al., "Mesoscopic CH3NH3PbI3/$\mathrm{TiO} 2$ heterojunction solar cells," Journal of the American Chemical Society, vol. 134, no. 42, pp. 17396-17399, 2012.

[3] M. A. Green, A. Ho-Baillie, and H. J. Snaith, "The emergence of perovskite solar cells," Nature Photonics, vol. 8, no. 7, pp. 506-514, 2014.

[4] E. Yablonovitch, "Lead halides join the top optoelectronic league," Science, vol. 351, no. 6280, p. 1401, 2016.

[5] J. Burschka, N. Pellet, S.-J. Moon et al., "Sequential deposition as a route to high-performance perovskite-sensitized solar cells," Nature, vol. 499, no. 7458, pp. 316-319, 2013.

[6] W. S. Yang, B. W. Park, E. H. Jung et al., "Iodide management in formamidinium-lead-halide-based perovskite layers for efficient solar cells," Science, vol. 356, no. 6345, pp. 13761379, 2017.

[7] G. E. Eperon, S. D. Stranks, C. Menelaou, M. B. Johnston, L. M. Herz, and H. J. Snaith, "Formamidinium lead trihalide: a broadly tunable perovskite for efficient planar heterojunction solar cells," Energy \& Environmental Science, vol. 7, no. 3, p. 982, 2014.

[8] N. K. Noel, S. D. Stranks, A. Abate et al., "Lead-free organicinorganic tin halide perovskites for photovoltaic applications," Energy \& Environmental Science, vol. 7, no. 9, pp. 3061-3068, 2014.

[9] S. A. Kulkarni, T. Baikie, P. P. Boix, N. Yantara, N. Mathews, and S. Mhaisalkar, "Band-gap tuning of lead halide perovskites using a sequential deposition process," Journal of Materials Chemistry A, vol. 2, no. 24, pp. 9221-9225, 2014.

[10] M. M. Lee, J. Teuscher, T. Miyasaka, T. N. Murakami, and H. J. Snaith, "Efficient hybrid solar cells based on meso- superstructured organometal halide perovskites," Science, vol. 338, no. 6107, pp. 643-647, 2012.

[11] E. Mosconi and F. De Angelis, "Mobile ions in organohalide perovskites: interplay of electronic structure and dynamics," ACS Energy Letters, vol. 1, no. 1, pp. 182-188, 2016.

[12] D. Weber, “ $\mathrm{CH} 3 \mathrm{NH} 3 \mathrm{PbX} 3$, ein $\mathrm{Pb}$ (II)-System mit kubischer Perowskitstruktur / $\mathrm{CH} 3 \mathrm{NH} 3 \mathrm{PbX} 3$, a $\mathrm{Pb}(\mathrm{II})$-system with cubic perovskite structure," Zeitschrift für Naturforschung B, vol. 33, no. 12, pp. 1443-1445, 1978.

[13] P. Jena, "Beyond the periodic table of elements: the role of superatoms," Journal of Physical Chemistry Letters, vol. 4, no. 9, pp. 1432-1442, 2013.

[14] A. Amat, E. Mosconi, E. Ronca et al., Nano Lett, 2014.

[15] F. Wang, H. Yu, H. Xu, and N. Zhao, "HPbI3: a new precursor compound for highly efficient solution-processed perovskite solar cells," Advanced Functional Materials, vol. 25, no. 7, pp. 1120-1126, 2015.

[16] S. Pang, Y. Zhou, Z. Wang et al., “Transformative evolution of organolead triiodide perovskite thin films from strong roomtemperature solid-gas interaction between $\mathrm{HPbI} 3-\mathrm{CH} 3 \mathrm{NH} 2$ precursor pair," Journal of the American Chemical Society, vol. 138, no. 3, pp. 750-753, 2016.

[17] W. Ke, I. Spanopoulos, C. C. Stoumpos, and M. G. Kanatzidis, "Myths and reality of $\mathrm{HPbI}_{3}$ in halide perovskite solar cells," Nature Communications, vol. 9, no. 1, p. 4785, 2018.

[18] M. Daub and H. Hillebrecht, "On the Demystification of " $\mathrm{HPbI}_{3}$ " and the Peculiarities of the Non-innocent Solvents $\mathrm{H}_{2} \mathrm{O}$ and DMF," Zeitschrift für anorganische und allgemeine Chemie, vol. 644, no. 22, pp. 1393-1400, 2018.

[19] A. Jain, S. P. Ong, G. Hautier et al., "Commentary: The Materials Project: a materials genome approach to accelerating materials innovation," APL Materials, vol. 1, no. 1, article 011002, 2013.

[20] A. Poglitsch and D. Weber, "Dynamic disorder in methylammoniumtrihalogenoplumbates (II) observed by millimeterwave spectroscopy," The Journal of Chemical Physics, vol. 87, no. 11, pp. 6373-6378, 1987.

[21] M. Becker and M. Wark, "Organic cation substitution in hybrid perovskite $\mathrm{CH} 3 \mathrm{NH} 3 \mathrm{PbI} 3$ with hydroxylammonium (NH3OH+): a first-principles study," The Journal of Physical Chemistry C, vol. 122, no. 6, pp. 3548-3557, 2018.

[22] G. Giorgi, J.-I. Fujisawa, H. Segawa, and K. Yamashita, "Organic-inorganic hybrid lead iodide perovskite featuring zero dipole moment guanidinium cations: a theoretical analysis," The Journal of Physical Chemistry C, vol. 119, no. 9, pp. 4694-4701, 2015.

[23] M.-G. Ju, J. Dai, L. Ma, and X. C. Zeng, "Lead-free mixed tin and germanium perovskites for photovoltaic application," Journal of the American Chemical Society, vol. 139, no. 23, pp. 8038-8043, 2017.

[24] A. Stroppa, C. Quarti, F. De Angelis, and S. Picozzi, "Ferroelectric polarization of $\mathrm{CH} 3 \mathrm{NH} 3 \mathrm{PbI} 3$ : a detailed study based on density functional theory and symmetry mode analysis," Journal of Physical Chemistry Letters, vol. 6, no. 12, pp. 2223-2231, 2015.

[25] L. Li, M. Wu, and X. C. Zeng, "Facile and Versatile Functionalization of Two-Dimensional Carbon Nitrides by Design: Magnetism/Multiferroicity, Valleytronics, and Photovoltaics," Advanced Functional Materials, vol. 29, no. 43, p. 1905752, 2019. 
[26] Z. Tu and M. Wu, "2D diluted multiferroic semiconductors upon intercalation," Advanced Electronic Materials, vol. 5, no. 6, p. 1800960, 2019.

[27] M. Wu and X. C. Zeng, "Bismuth oxychalcogenides: a new class of ferroelectric/ferroelastic materials with ultra high mobility," Nano Letters, vol. 17, no. 10, pp. 6309-6314, 2017.

[28] M. Wu, S. Dong, K. Yao, J. Liu, and X. C. Zeng, "Ferroelectricity in covalently functionalized two-dimensional materials: integration of high-mobility semiconductors and nonvolatile memory," Nano Letters, vol. 16, no. 11, pp. 7309-7315, 2016.

[29] D. B. Mitzi, C. D. Dimitrakopoulos, and L. L. Kosbar, "Structurally tailored organic-inorganic perovskites: optical properties and solution-processed channel materials for thin-film transistors," Chemistry of Materials, vol. 13, no. 10, pp. 3728-3740, 2001.

[30] Y. Zhang, R. Wang, Y. Li et al., "Optical Properties of TwoDimensional Perovskite Films of (C6H5C2H4NH3)2[PbI4] and (C6H5C2H4NH3)2(CH3NH3)2[Pb3I10]," Journal of Physical Chemistry Letters, vol. 10, no. 1, pp. 13-19, 2019.

[31] B. Kim and S. I. Seok, Energy \& Environmental Science, 2020.

[32] K. Kwak, E. Lim, N. Ahn et al., "An atomistic mechanism for the degradation of perovskite solar cells by trapped charge," Nanoscale, vol. 11, no. 23, pp. 11369-11378, 2019.

[33] G. Kresse and J. Furthmüller, "Efficiency of ab-initio total energy calculations for metals and semiconductors using a plane-wave basis set," Computational materials Science, vol. 6, no. 1, pp. 15-50, 1996.

[34] G. Kresse and J. Furthmüller, "Efficient iterative schemes forab initiototal-energy calculations using a plane-wave basis set," Physical Review B, vol. 54, no. 16, pp. 11169-11186, 1996.

[35] P. E. Blöchl, "Projector augmented-wave method," Physical Review B, vol. 50, no. 24, pp. 17953-17979, 1994.

[36] J. P. Perdew, K. Burke, and M. Ernzerhof, "Generalized gradient approximation made simple," Physical Review Letters, vol. 77, no. 18, pp. 3865-3868, 1996.

[37] H. J. Monkhorst and J. D. Pack, "Special points for Brillouinzone integrations," Physical Review B, vol. 13, no. 12, pp. 5188-5192, 1976.

[38] J. Heyd, G. E. Scuseria, and M. Ernzerhof, "Hybrid functionals based on a screened Coulomb potential," The Journal of chemical physics, vol. 118, no. 18, pp. 8207-8215, 2003.

[39] H. Beck, C. Gehrmann, and D. A. Egger, "Structure and binding in halide perovskites: analysis of static and dynamic effects from dispersion-corrected density functional theory," $A P L$ Materials, vol. 7, no. 2, article 021108, 2019.

[40] L. N. Anderson, F. W. Aquino, A. E. Raeber, X. Chen, and B. M. Wong, "Halogen Bonding Interactions: Revised Benchmarks and a New Assessment of Exchange vs Dispersion," Journal of Chemical Theory and Computation, vol. 14, no. 1, pp. 180-190, 2018.

[41] S. Grimme, "Semiempirical GGA-type density functional constructed with a long-range dispersion correction," Journal of Computational Chemistry, vol. 27, no. 15, pp. 1787-1799, 2006.

[42] R. D. King-Smith and D. Vanderbilt, "Theory of polarization of crystalline solids," Physical Review B, vol. 47, no. 3, pp. 1651-1654, 1993. 